\title{
Heterogeneous crustal deformation along the central-northern Itoigawa-Shizuoka Tectonic Line Fault system, Central Japan
}

\author{
Takeshi Sagiya ${ }^{1}$, Takuya Nishimura ${ }^{2}$, and Yoshihisa Iio $^{3}$ \\ ${ }^{1}$ Graduate School of Environmental Studies, Nagoya University, Furo-cho, Chikusa-ku, Nagoya 464-8602, Japan \\ ${ }^{2}$ Geographical Survey Institute, 1 Kitasato, Tsukuba 305-0811, Japan \\ ${ }^{3}$ Disaster Prevention Research Institute, Kyoto University, Gokasho, Uji 611-0011, Japan
}

(Received June 13, 2004; Revised October 18, 2004; Accepted November 28, 2004)

\begin{abstract}
We investigated the crustal deformation around the northern Itoigawa-Shizuoka Tectonic Line Fault Zone by continuous observation with a dense GPS array. The observation revealed concentrated deformation around the East Matsumoto-Basin Fault while the more active Gofukuji Fault has smaller strain rate. By examining the physical meanings of geodetic strain rate and the geological slip rate data, we estimate a larger seismic potential around the Gofukuji Fault. The deep slip model proposed for the strain concentration around the Omachi area was not validated. Inelastic deformation may play an important role as a cause of strain concentration.
\end{abstract}

Key words: Itoigawa-Shizuoka Tectonic Line Fault System, GPS, crustal deformation, strain concentration, tectonic loading.

\section{Introduction}

The Itoigawa-Shizuoka Tectonic Line (ISTL) is a major geologic boundary dividing the Japan Island arc into the northeastern and the southwestern parts. A series of active faults called the Itoigawa-Shizuoka Tectonic Line fault system is located along ISTL. The ISTL fault system is considered to be one of the most active faults in the Japan Islands. According to Okumura (2001), the Gofukuji Fault at the central part of the ISTL fault system is primarily a left-lateral strike slip fault with an average slip rate of about $9 \mathrm{~mm} / \mathrm{yr}$. On the other hand, the East Matsumoto Basin Fault and the Kamishiro Fault at the northern ISTL fault system are reverse faults, and their slip rate is estimated to be around $3 \mathrm{~mm} / \mathrm{yr}$. Thus the deformation style along the ISTL fault system is laterally heterogeneous in the geological time scale.

In this study, we discuss the crustal deformation around the central-northern ISTL fault system by means of geodetic observation. Recent development of GPS (Global Positioning System) technology realized a quasi-real-time monitoring of the earth's surface deformation with a few millimeter precision. Sagiya et al. (2002) established a dense array of continuous GPS observation sites around the centralnorthern ISTL fault system and discussed initial results from the GPS array until December 2001. Here we summarize GPS observation results thereafter and discuss implications of the present deformation pattern in conjunction with the tectonic loading process of active faults along ISTL.

Copy right(c) The Society of Geomagnetism and Earth, Planetary and Space Sciences (SGEPSS); The Seismological Society of Japan; The Volcanological Society of Japan; The Geodetic Society of Japan; The Japanese Society for Planetary Sciences; TERRAPUB

\section{Continuous GPS Observation}

Sagiya et al. (2002) established a dense array of 11 continuous GPS stations around the central-northern ISTL fault system in 1999-2000. Because of the high probability of large earthquakes deduced for the Gofukuji Fault (Headquarters for Earthquake Research Promotion, 1996), a number of continuous GPS sites had been installed in this region in 1997. However, the distribution of those GPS sites was not necessarily suitable for investigating the tectonic loading process of the ISTL fault system because they were located mostly along the surface trace of the fault. Such a GPS array would be useful in resolving coseismic slip distribution of large earthquakes, or in detecting a surface creep of the fault, if any. When the fault is completely locked, however, this type of GPS array is not efficient since relative deformation within the small aperture array is very small. Therefore new GPS stations were installed to form a $100 \mathrm{~km}$-long linear array across the fault together with existing GPS sites. For this main array (heareafter called the Omachi Linear Array (OLA), see Fig. 1 for location), 9 new GPS stations were aligned in the WNW-ESE direction, crossing ISTL around the Omachi city. Along OLA, a magetotelluric survey and seismic reflection/refraction surveys were conducted to reveal the deep crustal structure (Ogawa et al., 2002; Sato et al., 2004; Imai et al., 2004). On the other hand, two other GPS stations were newly installed around the Gofukuji Fault, as a part of the Matsumoto Linear Array (MLA). In total, 42 continuous GPS sites formed a dense continuous GPS array around the central-northern ISTL fault system (Fig. 1).

GPS observation data were analyzed to yield daily coordinates of each station. We used the Bernese GPS software version 4.2 (Hugentobler et al., 2001) and the precise orbit of GPS satellites provided by the International GPS Service (http://igscb.jpl.nasa.gov/) for our data analysis. Figure 2 

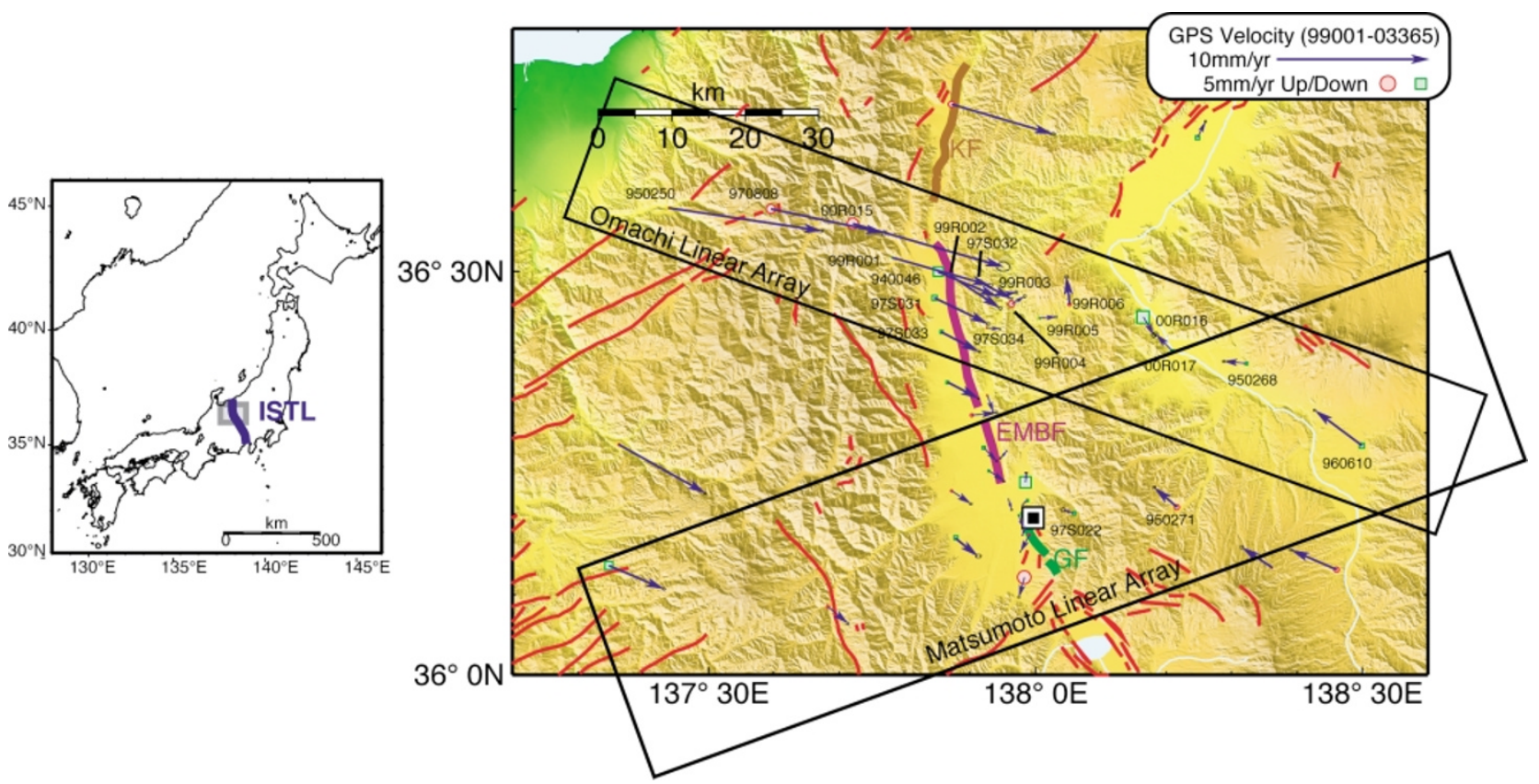

$36^{\circ} \mathrm{ON}$

Fig. 1. (Left) Location of the Itoigawa-Shizuoka Tectonic Line (ISTL) is shown by a thick blue line. A gray rectangle around the central-northern ISTL denotes the present study area. (Right) Displacement rate vectors around the central-northern ISTL fault system estimated from continuous GPS observation from January 1998 to December 2003. Station 97S022 is assumed to be fixed. Rectangles indicate two GPS linear arrays for which displacement rate profiles are shown in Fig. 3. GF: Gofukuji Fault, EMBF: East Matsumoto Basin Fault, KF: Kamishiro Fault. Thin red lines denote active faults.
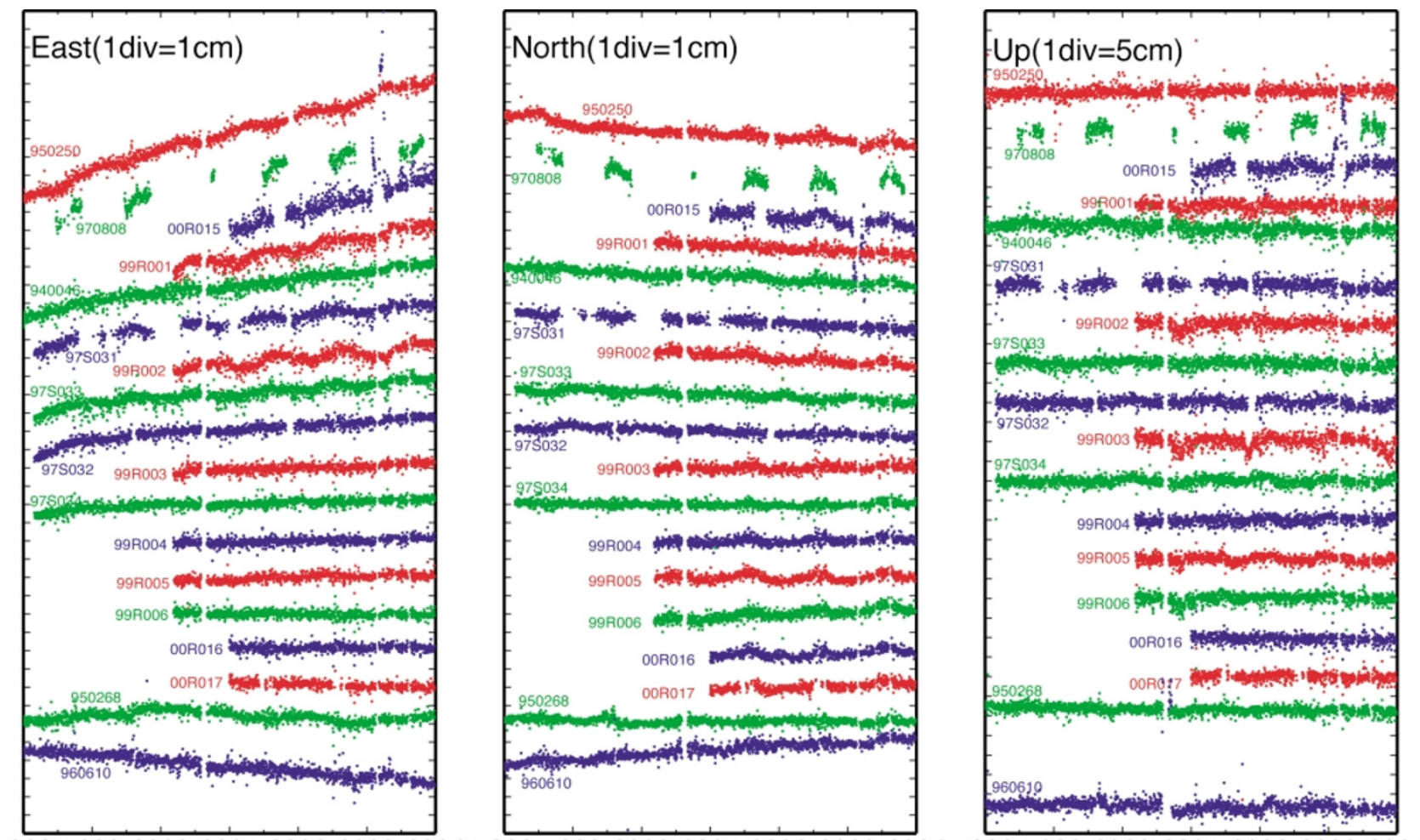

199819992000200120022003200419981999200020012002200320041998199920002001200220032004

Fig. 2. Daily coordinate time series of GPS stations in the northern ISTL with respect to the station 950271. Please refer Fig. 1 for the location of each station.

shows a time series plot of daily coordinate changes (with respect to 950271) for the stations in the Omachi Linear Array from January 1998 to December 2003. We can clearly identify a gradual trend change from station to station in the E-W and the N-S components. That is, the stations in the northwestern part move southeastward and those in the southeastern part move northwestward. In other words, there is a significant shortening taking place along the lin- 
ear array. At the beginning of the time series in 1998, the E-W displacement rate seems to have changed at several stations (e.g. 97S032 and 97S033). Probably these changes are associated with the seismic swarm activity in the Hida Mountains starting August 1998 (Aoyama et al., 2002). It is interesting to see that the effect of this swarm activity was not a step-like one but a trend change. We need more detailed investigation for this deformation in the future. At station 950268, E-W displacement time series show irregular changes, which may be attributed to a volcanic activity of Mt. Asama.

We calculated a displacement rate for each GPS station by fitting the daily displacement time series by a linear trend with seasonal signals. The displacement rate is obtained as a slope of the linear trend for each component. Here seasonal signals were approximated as a linear combination of sine and cosine functions whose frequency is an arbitrary positive integer (The unit of time is year in this context.). The maximum integer frequency was selected by using AIC (Akaike, 1973).

Figure 1 shows displacement rate vectors at all the analyzed sites. More than $10 \mathrm{~mm} / \mathrm{yr}$ shortening evidently occurs along the Omachi Linear Array. On the other hand, the central part around the Gofukuji Fault does not have so much shortening. Rather, left-lateral shear deformation seems dominant in this area. It is worthwhile to point out that we do not detect significant vertical deformation at the majority of the stations. However, there are two sites showing large uplift rates in the Hida Mountains (the northern Japan Alps). The accuracy of a vertical displacement rate at these stations is not quite high because the number of daily coordinate solutions is smaller than those of other stations and these stations are subject to more tropospheric errors due to their high altitudes. In spite of these problems, the observation still implies the possibility of a contemporary uplift of Hida Mountains at 3-4 mm/yr.

In order to take a close look at displacement rate distribution, velocity profiles were created along two lines, denoted as Omachi and Matsumoto Linear Arrays shown in Fig. 1. Horizontal displacement vectors are decomposed into two components referring to the alignment of the stations. In OLA, the N110E component of the displacement rate drastically changes by $10 \mathrm{~mm} /$ year within about $30 \mathrm{~km}$ around the GPS site 940046 . The linear strain rate becomes as large as about $0.3 \mathrm{ppm} / \mathrm{yr}$ around Omachi whereas it is smaller by an order of magnitude in the surrounding areas. On the other hand, the N20E component shows almost no change. It is worthwhile to notify that the N110E direction is oblique to the strike of the East Matsumoto Basin Fault, indicating that the fault has a significant left-lateral slip component. By assuming the fault strike as N170W, the fault-parallel component of the relative displacement rate vector between two crustal blocks separated by the fault becomes about 5 $\mathrm{mm} / \mathrm{yr}$ in the left-lateral direction. The fault-normal component is an $8 \mathrm{~mm} / \mathrm{yr}$ of contraction. The vertical components are much noisier than the horizontal component. The significant level of vertical displacement rate is about $2 \mathrm{~mm} / \mathrm{yr}$. In addition, multiple neighboring stations need to have similar values. The only possibility of significant uplift is found at the two stations in the Hida Mountains as described before.
Along MLA, we see both contraction (N70E component) and left-lateral shear (N20W component) across the fault. Changes in the N20W component are more significant, which is consistent with the large left-lateral slip rate of the Gofukuji Fault (Okumura, 2001). In Fig. 3, displacement rate change around the Gofukuji Fault does not look concentrated around the fault trace. Rather, a $100 \mathrm{~km}$ wide area around the fault is deformed in an almost uniform manner. This situation is quite different from the concentrated deformation found along OLA. We will discuss the meaning of this deformation pattern later. We do not see significant vertical displacement around the Matsumoto area.

We also calculate a strain rate distribution of this area based on displacement rate data with the same method as Sagiya et al. (2000). Figure 4 shows the distribution of dilatation rate with principal strain rate axes. We can clearly identify an area of large compression (about $0.2 \mathrm{ppm} / \mathrm{yr}$ ) in the northern half of this figure, around the Omachi city. On the other hand, the Matsumoto city area has much smaller compression (about $0.05 \mathrm{ppm} / \mathrm{yr}$ ), with a significant amount of shear strain rate (about $0.2 \mathrm{ppm} / \mathrm{yr}$ left-lateral shear along the fault trace of ISTL).

\section{Comparison of the Gofukuji Fault and the East Matsumoto Basin Fault}

The GPS observation demonstrates quite heterogeneous strain rate distribution along the central-northern ISTL fault system. Comparing the Gofukuji Fault at the central ISTL fault system and the East Matsumoto Basin Fault in the northern part, the former has a larger geological slip rate, and the latter has a larger geodetic strain rate. These results seem to be inconsistent with each other. However, we would like to argue that it is not the case and there are important implications for tectonic loading processes of these faults.

Bourne et al. (1998) compared a displacement rate profile across a fault zone based on geological slip rate data and another profile based on geodetic observation in two locations, the South Island of New Zealand and southern California. They demonstrated these two different datasets are fairly consistent each other, that is, the geodetic profile was a smoothed curve of the stepwise geological profile. If we apply the same idea to inland active faults, we expect that the two crustal blocks separated by an active fault should have a long-term relative displacement rate comparable to the geological slip rate of the active fault. It is worthwhile to examine if such an idea is applicable to the present study area.

When we apply the above idea to the central-northern ISTL fault system, we obtain an interesting result. In the northern ISTL at the East Matsumoto Basin Fault, it is apparent that relative shortening between the southeastern and the northwestern blocks is accommodated in a very narrow (about $30 \mathrm{~km}$ ) zone near the East Matsumoto Basin fault. If this deformation reflects an elastic strain accumulation, the effective thickness of the surface elastic layer is estimated as thinner than $10 \mathrm{~km}$ (Sagiya et al., 2002). In addition, relative contraction across the fault is as large as $10 \mathrm{~mm} / \mathrm{yr}$, at least 3 times as large as the geological slip rate. These results cannot be explained in a framework of the elastic 

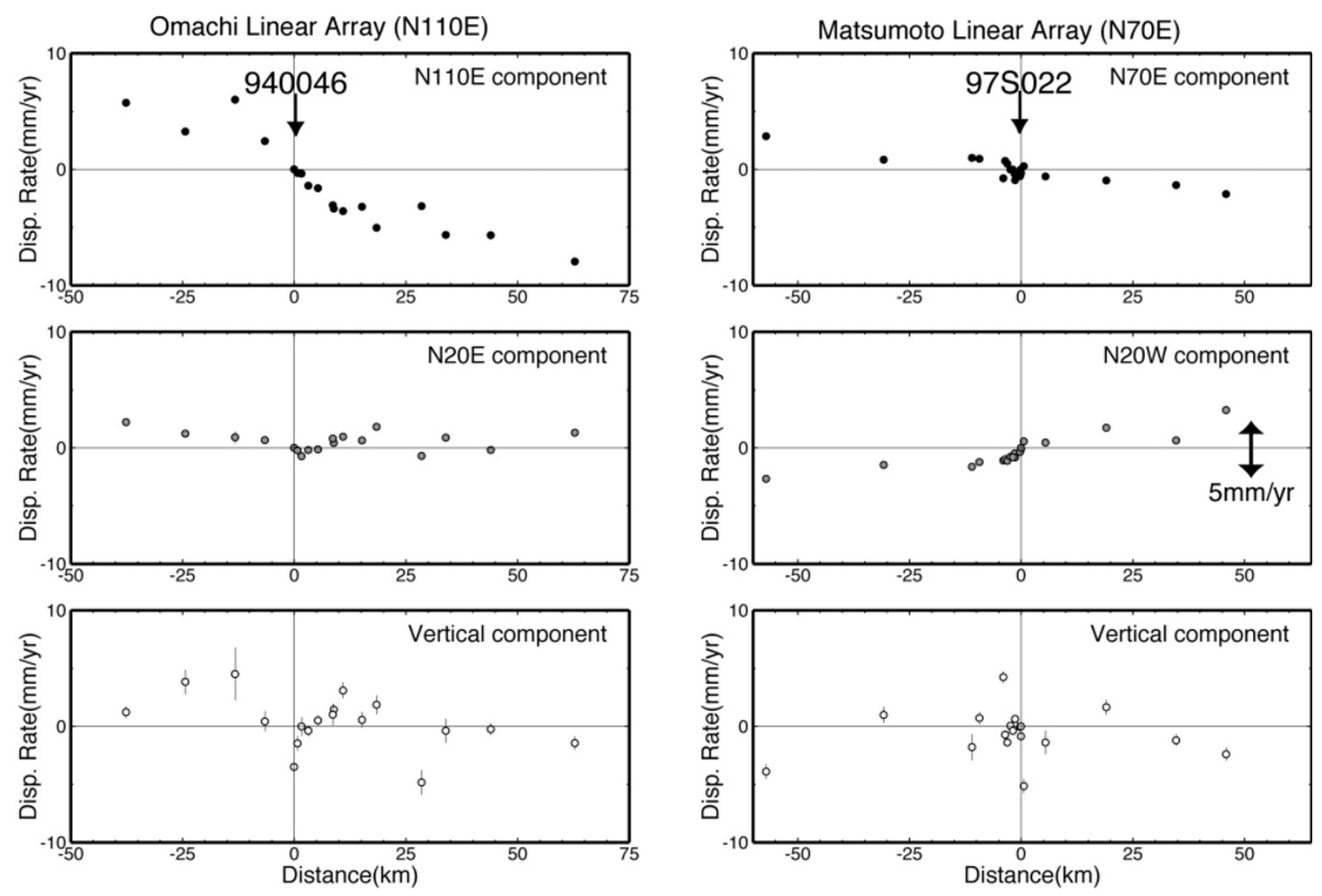

Fig. 3. Displacement rate profile for 2 GPS linear arrays. See Fig. 1 for location of each array. Vertical component data of the Omachi Linear array are shifted by $+4 \mathrm{~mm} / \mathrm{yr}$ in order to correct for the local subsidence at Omachi (9400046) station.

upper crust loaded by a differential motion of neighboring two blocks. It is necessary to incorporate other factors, such as an inelastic deformation, for the interpretation.

Around the Omachi city, the Omachi earthquake, a doublet event of magnitude 6 earthquakes, occurred in 1918 . Sagiya (2003) analyzed the coseismic displacement data and estimated a fault model consistent with the long-term as well as contemporary crustal deformation in this area. The estimated fault model was a low-angle thrust mechanism and was located at the base of the Matsumoto Basin, branched off from the East Matsumoto Basin Fault to the west. The 1918 Omachi earthquake was considered to have ruptured the shallowest part of the upper crust. This fault model suggests that strain release in this area is not confined at the East Matsumoto Basin Fault, but distributed to the surrounding area. At the deeper part, some inelastic process may take place to accommodate the contraction because the apparent elastic thickness in this region is so thin. As a supporting evidence of this hypothesis, deeply penetrated basin sediments were identified along the deeper extension of the East Matsumoto Basin Fault down to $5 \mathrm{~km}$ by Takeda et al. (2004). Such a structure may be responsible for the anomalous crustal deformation observed in this area. Taking the small effective thickness of the surface elastic layer and a possibility of inelastic deformation around Omachi into account, this area probably does not have a potential for a future large earthquake over magnitude 7 in spite of the large strain rate observed.

On the other hand, around the Matsumoto city near the
Gofukuji Fault, displacement rate changes rather gradually and the geodetic strain rate is comparatively small. If we compare displacement rate data at two points about $100 \mathrm{~km}$ apart, the relative displacement rate becomes as large as 5-8 $\mathrm{mm} / \mathrm{yr}$, comparable in value to the geological slip rate. This result indicates that elastic strain is accumulated in a wide area around the Gofukuji Fault.

It is worthwhile to note that we should strictly distinguish slip rate (or displacement rate) data from strain rate data. Since the latter is spatial derivative of the former, it does not make any sense to compare these two values directly. Also, we have to be careful to interpret strain rate data in terms of a seismic potential. As a simple example, the strain rate becomes infinite at a creeping fault that has essentially no potential for future large earthquakes.

It is possible to define a geodetic fault zone width (GFZW) as the distance across the fault with which the relative geodetic displacement rate equals the geological slip rate. Such a parameter can be used to characterize each active fault in terms of tectonic loading. In the case of the central-northern ISTL fault system, GFZW is about $10 \mathrm{~km}$ for the East Matsumoto Basin Fault and about $100 \mathrm{~km}$ for the Gofukuji Fault. Of course, the larger value at the Gofukuji Fault implies a wider locked zone and possibilities of larger earthquakes.

\section{Discussion}

Ogawa et al. (2002) and Ogawa and Honkura (2004) conducted magtetotelluric surveys to image resistivity structure 


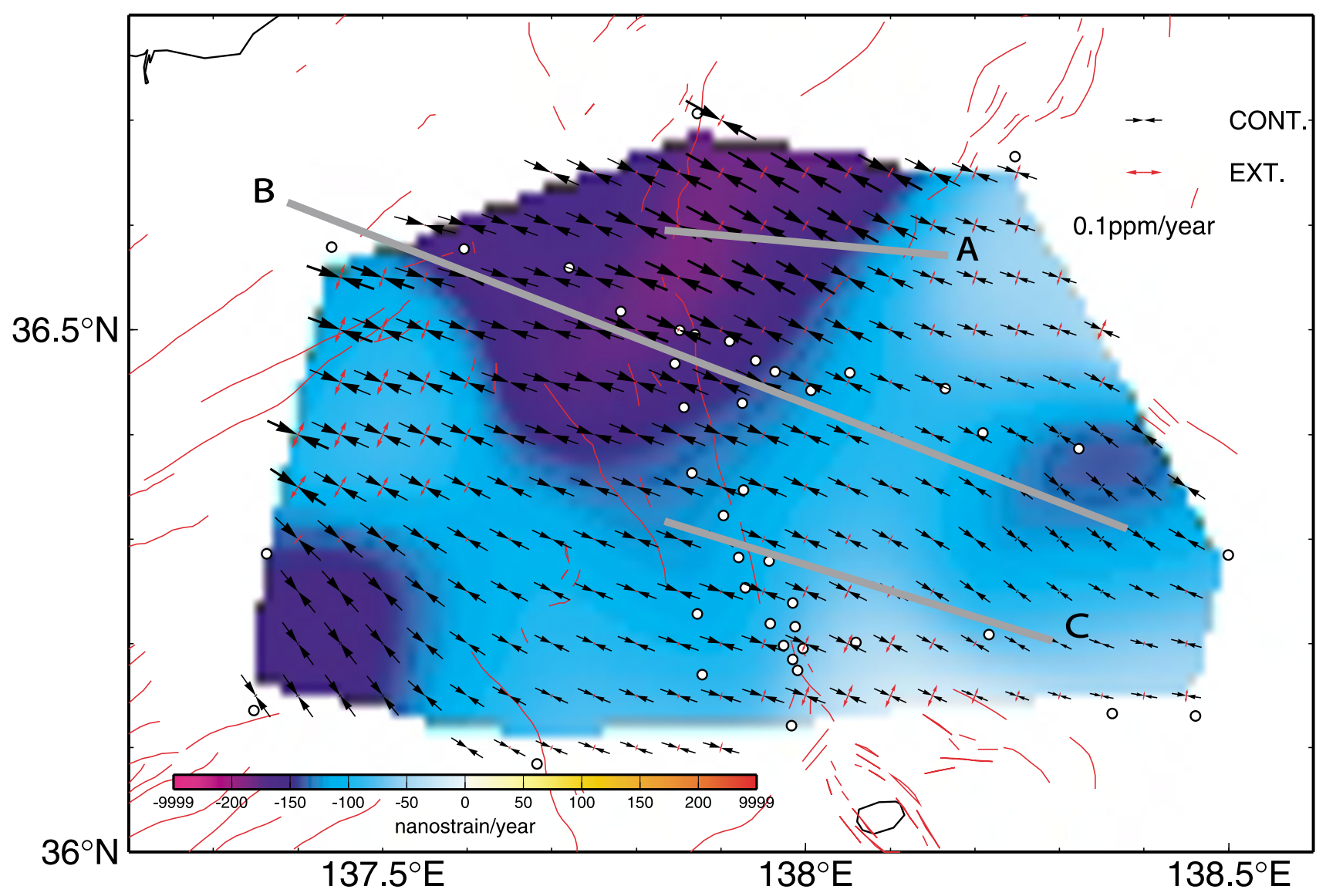

Fig. 4. Dilatation rate and principal strain rate axes around the central-northern ISTL estimated from GPS displacement rate data. Gray lines indicate magnetotelluric survey lines by Ogawa et al. (2002) and Ogawa and Honkura (2004). Thins red lines denote active faults.

of the upper as well as lower crust along three survey lines across the central-northern ISTL fault system. Their results showed that sedimentary layers in the Matsumoto Basin and the heavily folded oceanic sediments in the Minochi Belt have low resistivity. In addition, they found a lowresistivity region in the lower crust below the high strain zone detected by GPS observation. However, such a low resistivity region in the lower crust was not identified along the southernmost survey line, consistent with the smaller strain rate at the surface. These results suggest a possible cause of strain concentration zone. Low resistivity indicates an existence of crustal fluid, which alters the rheological property of the crustal material (Ogawa et al., 2002). Such a property change may play an important role in creating the strain concentration zone at the surface. Iio et al. (2002) proposed such a mechanism for the generation of the Niigata-Kobe Tectonic Zone (Sagiya et al., 2000), a strain concentration zone located along the Japan Sea coast in the northeast Japan and in the northern part of central Japan.

On the other hand, Sato et al. (2004) deduced that the deeper extension of the East Matsumoto Basin Fault extends to the east with a shallow angle, reaching the bottom of the upper crust more than $50 \mathrm{~km}$ east of its surface trace. It is difficult to interpret the strain concentration at the surface trace in conjunction with a physical process at the deeper extension of the fault. Sagiya et al. (2002) proposed a model of deep slip at the deeper fault extension in order to interpret the horizontal strain concentration. Those models were successful in reproducing the horizontal deformation pattern, but at the same time, they predicted significant uplift on the eastern side of the fault, which are not observed. Therefore, with the fault geometry by Sato et al. (2004), the deep fault slip model cannot be accepted as a possible mechanism for the strain concentration. Rather, the strain concentration should be interpreted as associated with the deeper crustal heterogeneity just beneath the concentrated deformation.

These discussions now invoke a necessity for further modeling effort to reproduce the observed deformation pattern. Since various structural data are available from exploration surveys, we can make use of them. Now we are trying finite element modeling by incorporating heterogeneous crustal structure, testing various boundary conditions, to reproduce the observed deformation pattern. The results of the modeling effort will be published as a separate study in the future.

Acknowledgments. We appreciate efforts for operating the Japanese continuous GPS network (GEONET) by the GPS group of the Geographical Survey Institute. This study was conducted as a part of the "Comprehensive Research on Slip and Flow Processes in and below the Seismogenic Region" supported by the Special Coordination Fund of the Ministry of Education, Culture, Sport, Science and Technology (MEXT). The paper was significantly improved by comment of two referees (Dr. Bruce Hobbs and Prof. Satoshi Miura) and the associate editor (Prof. Yasuo Ogawa). 


\section{References}

Akaike, H., Information theory and an extension of the maximum likelihood principle, Proc. 2nd Inter. Symp. on Information Theory (Petrov, B. N. and Csaki, F. eds.), Akademiai Kiado, Budapest, 267-281, 1973.

Aoyama, H., M. Takeo, and S. Ide, Evolution mechanism of an earthquake swarm under the Hida Mountains, central Japan, in 1998, J. Geophys. Res., 107, 2174, doi:10.1029/2001JB000540, 2002.

Bourne, S. J., P. C. England, and B. Parsons, The motion of crustal blocks driven by flow of the lower lithosphere and implications for slip rates of continental strike-slip faults, Nature, 391, 655-659, 1998.

Headquarters for Earthquake Research Promotion, Investigation results and evaluation of the Itoigawa-Shizuoka Tectonic Line fault system, September 11, 1996 (in Japanese).

Hugentobler, U., S. Schaer, and P. Fridez (eds.), Bernese GPS Software Version 4.2, University of Berne, 515 pp., 2001.

Iio, Y., T. Sagiya, Y. Kobayashi, and I. Shiozaki, Water-weakened lower crust and its role in the concentrated deformation in the Japanese Islands, Earth Planet. Sci. Lett., 203, 245-253, 2002.

Imai, T., T. Iwasaki, T. Takeda, T. Kawanaka, and H. Sato, Detailed upper crustal structure across the Itoigawa-Shizuoka Tectonic Line from the 2002 seismic expedition, Japan Earth Planet. Sci. Joint Meeting, S075$005,2004$.

Ogawa, Y., S. Takakura, and Y. Honkura, Resistivity structure across Itoigawa-Shizuoka tectonic line and its implications for concentrated deformation, Earth Planets Space, 54, 1115-1120, 2002.
Ogawa Y. and Y. Honkura, Mid-crustal electrical conductors and their correlations to seismicity and deformation at Itoigawa-Shizuoka Tectonic Line, Central Japan, Earth Planets Space, 56, this issue, 1287-1293, 2004.

Okumura, K., Paleoseismology of the Itoigawa-Shizuoka tectonic line in central Japan, J. Seismol., 5, 411-431, 2001.

Sagiya, T., S. Miyazaki, and T. Tada, Continuous GPS array and presentday crustal deformation of Japan, PAGEOPH, 157, 2302-2322, 2000

Sagiya, T., T. Nishimura, Y. Iio, and T. Tada, Crustal deformation around the northern and central Itoigawa-Shizuoka Tectonic Line, Earth Planets Space, 54, 1059-1063, 2002.

Sagiya, T., A new fault model for the 1918 Omachi Earthquake-Leveling data revision and integrated interpretation of multi-disciplinary data-, Zisin, 56, 199-211, 2003 (in Japanese with English abstract).

Sato, H., T. Iwasaki, S. Kawasaki, Y. Ikeda, N. Matsuta, T. Takeda, N. Hirata, and T. Kawanaka, Formation and shortening deformation of a back-arc rift basin revealed by deep seismic profiling, central Japan, Tectonophys., 2004 (submitted).

Takeda, T., H. Sato, T. Iwasaki, N. Matsuta, S. Sakai, and T. Iidaka, Crusta structure in the northern part of Fossa magna region, central Japan, from refraction/wide-angle reflection data, Japan Earth Planet. Sci. Joint Meeting, S075-006, 2004.

T. Sagiya (e-mail: sagiya@seis.nagoya-u.ac.jp) 